\section{Conflicto, religión y educación religiosa en Colombia*}

\author{
Jaime Laurence Bonilla Morales **
}

RECIBIDO: 20-08-15. APROBADO: 22-11-15

Resumen: El conflicto, desde las perspectivas de violencia y paz, es un tema capital en nuestro contexto. El problema demanda tratamiento interdisciplinar y en ese marco es importante considerar la responsabilidad de las instituciones religiosas, la teología y la educación religiosa, pues estas poseen argumentos, experiencias, potencialidades, enfoques y valores capaces de transformar las tendencias violentas y de reconducir los distintos conflictos hacia una cultura de paz.

Palabras Clave: Conflicto, paz, violencia, educación religiosa, Colombia.

PARA CITAR ESTE ARTÍCULO:

Bonilla Morales, Jaime L. "Conflicto, religión y educación religiosa en Colombia”. Theologica Xaveriana 181 (2016): 207-237. http://dx.doi.org/10.11144/ javeriana.tx66-181.crerc

\section{Conflict, Religion and Religious Education in Colombia}

Авstract: Considering the perspectives of violence and peace, the conflict is a main subject in our context. This problem requires an interdisciplinary treatment. In this frame, it is important to consider the responsibility of religious institutions, Theology and religious education, in the sense that they have the arguments, experiences, potentialities, approaches and values that are able to transform the violent tendencies, and to lead the different conflicts back to a culture of peace.

Key words: Conflict, peace, violence, religious education, Colombia.

\section{Conflito, religião e educação religiosa na Colômbia}

Resumo: O conflito, a partir das perspectivas de violência e paz, é um tema capital em nosso contexto. O problema demanda um tratamento interdisciplinar e nesse contexto é importante considerar a responsabilidade das instituiçôes religiosas, a teologia e a educação religiosa, pois estas possuem uma série de argumentos, experiências, potencialidades, abordagens e valores capazes de transformar as tendências violentas e de redirecionar os diferentes conflitos a uma cultura de paz. Palavra Chave: Conflito, paz, violência, educação religiosa, Colômbia.

\footnotetext{
* Resultado parcial del proyecto de investigación "Educación y religión: violencia y paz", del grupo de investigación Devenir, de la Facultad de Ciencias Humanas y Sociales de la Universidad San Buenaventura, Bogotá, en convenio con la Federación Internacional de Universidades Católicas, FIUC, y bajo la dirección del Observatorio para la Diversidad Religiosa y de las Culturas en América Latina y el Caribe, Odrec.

* Cursa el Doctorado en Artes y Humanidades: Teología, Universidad de Murcia (España); Magíster en Filosofía, Pontificia Universidad Javeriana, Bogotá; Licenciado en Filosofía y Licenciado en Teología, Universidad San Buenaventura, sede Bogotá. Profesor investigador, Universidad San Buenaventura, Bogotá. Correo electrónico: JBonilla@usbbog.edu.co; laurencebm@yahoo.es
} 
En el presente artículo se dará cuenta de la teoría del conflicto, desde el amplio horizonte que actualmente proporcionan las ciencias de la paz, para ilustrar algunas de las características de lo que en Colombia se conoce como conflicto-posconflicto; en seguida se expondrá una serie de reflexiones sobre las riquezas y potencialidades que se pueden procurar -desde la educación y las experiencias religiosas- para ampliar la discusión y las propuestas hacia una cultura de paz. El texto culminará con la presentación de algunos componentes esenciales que la educación religiosa (escolar y universitaria) puede asumir.

Teológicamente, esta reflexión se podría configurar inicialmente dentro de la teología pastoral, pero en conexión con una lectura crítica, sin desprenderse de sus elaboraciones teóricas, en cuanto asume el "reto de elaborar siempre la razonabilidad del acto humano, de la actividad, de la práctica y de la praxis para evitar la recurrente insuficiencia de razonabilidad, el practicismo, el inmediatismo, el decisionismo" ${ }^{1}$. Con esto se va más allá de una teología práctica o aplicada, del inmediatismo en el que no pocas veces ha caído el quehacer teológico latinoamericano, para dar paso a una teología de la acción que escudriña los horizontes de la paz y la educación, y al mismo tiempo tiene el siguiente fin:

La comprensión de la acción humana en sí misma considerada, su entidad, verdad, valor y finalidad en el plan de la salvación y la correspondiente animación teologal y teológica del hacer en el mundo, en la sociedad, en la Iglesia, en tanto que todo el constructo teórico y accionario de la teología de la acción está posibilitado y enderezado por el valor supremo del Reino y Reinado de Dios en la historia. ${ }^{2}$

\section{El marco de la teoría del conflicto}

Para empezar se optará por el enfoque propuesto por Johan Galtung, autoridad internacional en investigaciones sobre la paz. Primero, en cuanto su horizonte de pensamiento es catalogado como sistémico, muy cercano a la corriente del pensamiento complejo en distintos elementos; y segundo, casi como consecuencia del primer punto, este sociólogo considera que las investigaciones sobre la paz, la educación para la paz y las acciones de paz deben realizarse en apertura a la trascendencia, a las experiencias religiosas, en el reconocimiento de los aportes implícitos y explícitos presentes en sus tradiciones y manifestaciones.

\footnotetext{
${ }^{1}$ Parra, "De camino a la teología de la acción”, 151.

${ }^{2}$ Ibíd., 165-166.
} 
Ya que la reflexión sobre la paz de Galtung tiene como fundamento la "teoría del conflicto”, conviene desarrollarla en sus componentes esenciales. Así, para iniciar, es necesario afirmar que el conflicto aparece, de suyo, cuando hay alguna contradicción, ya sea por disputa o por dilema. Por disputa: cuando "dos personas o actores persiguen un mismo fin que escasea. Dilema: [cuando] una persona o actor persigue dos fines incompatibles entre sî"3.

Según esta teoría, inicialmente la disputa puede llevar a destruir a otro sujeto/ actor, mientras que el dilema puede llevar, por lo general, a la autodestrucción, aunque las consecuencias pueden ser aún mayores en cuanto cabe la posibilidad de que ambas generen a la larga tanto autodestrucción como destrucción del otro ${ }^{4}$. Estas fuentes de conflicto están presentes en la vida diaria y se convierten en la manera como se libera una suerte de energía. El reto consiste en encauzarla de la mejor manera posible, para que no se transforme en destrucción sino en construcción, pues cualquier otra opción que se aleje de la transformación creativa del conflicto puede terminar en distintos tipos de violencia ${ }^{5}$.

En el conflicto se pueden identificar tres componentes: "actitudes/presunciones + comportamiento + contradicción/contenido" ${ }^{6}(\mathrm{~A}+\mathrm{B}+\mathrm{C})$, en donde $\mathrm{A}$ y $\mathrm{C}$ son consideradas latentes, componentes teóricos, no manifiestos; mientras, lo inmediatamente observable o empírico es el comportamiento $\mathrm{B}$, pues se trata efectivamente de una realidad de seres vivos en relación. Por esto, el conflicto resulta algo esencial a la vida: solo si hay vida hay conflicto y si hay conflicto, hay vida.

Las dificultades se profundizan cuando la "contradicción" (algo deseado que se encuentra bloqueado) genera "agresividad como actitud y [especialmente] agresión

${ }^{3}$ Galtung, Paz por medios pacificos. Paz y conflicto, desarrollo y civilización, 107.

${ }^{4}$ Como ejemplo se puede pensar en la manera como la disputa, cuando desemboca en violencia, está presente en el mundo del deporte (aunque se aplique a todos los ámbitos de la vida). Así, un deportista "A" puede llegar a hacerle daño a quien se interponga en su camino (deportista "B"). Pero esta destrucción del otro, en la contienda por el mismo fin, podría también acarrear consecuencias personales (hacia el deportista "A"), en una especie de autodestrucción, ya que posiblemente no cumpla su objetivo al verse obligado a pagar una penalización por su acción destructiva, su imagen se vería afectada y estaría insatisfecho con la culpa o por el fracaso al no cumplir con su fin propuesto. De otra parte, se encuentra el dilema que viviría un deportista "A", al no tener claridad sobre la decisión que debe tomar ante dos fines incompatibles que se le presentan. Este escenario puede desembocar, si se rinde ante la violencia, en agresión hacia el otro, en una exteriorización de su frustración personal.

${ }^{5}$ Galtung, Paz por medios pacificos, 107-108.

${ }^{6}$ Ibíd., 108. En este mismo punto conviene mencionar que las actitudes tienen que ver con las emociones, mientras que las presunciones tienen que ver con las cogniciones. 
como conducta"', y se pasa así del conflicto hacia distintos tipos de violencia, que a su vez pueden reproducir en mayor o menor medida el mismo tipo de violencia $\mathrm{u}$ otros distintos, en un movimiento que pareciera replicarse de manera incesante, en una espiral abierta que refleja la complejidad humana. Aunque, ciertamente, la contradicción que hace parte de cualquier conflicto también puede ser causa de transformación y no tiene que manifestarse obligatoriamente por medio de la violencia ${ }^{8}$.

En el conjunto de taxonomías existentes sobre los conflictos se identifica el nivel de (1) conflictos "personales", conscientes, y (2) conflictos "estructurales", que son subconscientes.

Los conflictos personales son tales gracias al proceso de concienciación, que permite al ser humano ser más que un simple objeto del conflicto y convertirse en un sujeto consciente, capaz de conducir el proceso. La concienciación es una condición necesaria para hacerse una imagen del conflicto, pero no significa la solución directa o inmediata de los conflictos, pues siempre necesitan ser contrastados, ya que hay imágenes falsas que causarían confusión ${ }^{9}$.

Los conflictos estructurales no son conscientes, pues están dados sobre la base del subconsciente colectivo, así uno o más miembros del grupo tengan conciencia del bien o mal que hacen como líderes o directivos de un colectivo ${ }^{10}$.

Ahora bien, entre las múltiples posibilidades de generación y solución de conflictos pueden intervenir un sinnúmero de actores y objetivos, pero es el proceso de concienciación el encargado de llevar desde la frustración básica (no alcance de objetivos), a la conciencia del conflicto y su transformación. En esta afirmación hay una lectura compleja del conflicto que se refleja precisamente en la multitud de actores y objetivos proyectados, en sus posibles relaciones, así como en la capacidad de transformación e inclusión de distintas variables; por ello se considera que, mientras más complejo sea un conflicto, este tiene más posibilidades de encontrar trans-

${ }^{7}$ Ibíd., 109.

${ }^{8}$ Ibíd., 108-111.

${ }^{9}$ Aquí se evoca la obra de Paulo Freire, aunque no se desarrolle, pues este pensador trabajó el concepto de "conscientización", desde un énfasis más cultural y social. Ver a Freire, "Conscientization", 23-28. Y desde una lectura de la filosofía de la educación, ver a Villalobos, "Educación y concientización: legados del pensamiento y acción de Paulo Freire", 17-24.

${ }^{10}$ Galtung, Paz por medios pacíficos, 111-114. Aquí se aclara que el dilema da cuenta de la estructura de la personalidad y las disputas son dadas por la estructura social dentro de un sistema que conduce hacia el conflicto. Así mismo, conviene mencionar que para Galtung la concienciación de la mente y del cuerpo se da en el "espíritu". 
formaciones creativas. Sin embargo, hay quienes caen en la trampa de rechazar la complejidad del conflicto y optan por soluciones que lo simplifican o lo reducen, disminuyendo así las posibilidades de variación o transición ${ }^{11}$.

Este concepto de conflicto es dinámico, irreducible a una sola fórmula, a las bondades de la descripción intelectual o a aquellas logradas mediante pacto firmado, que es lo que más se difunde actualmente. Ciertamente, desde el proceso investigativo es posible acceder a la exposición pormenorizada de los actores o partes que intervienen en un conflicto, así como a las contradicciones que se presentan, pero siempre será un fenómeno humano escurridizo, por su carácter dinámico que no logra ni le interesan soluciones finales, sino transformaciones.

Este pareciera ser el carácter que constituye a cada individuo y la sociedad, que siempre se manifestará en forma de conflictos, transformándose constantemente, y el objetivo de quienes buscan la paz consistirá en acompañar estas transformaciones del conflicto de la manera más aceptable y sostenible posible, pues su disolución resultaría imposible ${ }^{12}$.

Si se admiten los argumentos hasta aquí expuestos, se estaría ante la inminente necesidad de desmontar o transformar el concepto común o básico de conflicto, que en distintos textos académicos y en el imaginario de las culturas ${ }^{13}$ sigue apareciendo como algo negativo, como componente de la vida necesario de evitar o acabar a toda costa, pues incluso se relaciona directamente con la violencia y la guerra.

Esta propuesta -por lo contrario-conlleva a considerar el conflicto como parte de la naturaleza humana, que hace parte de la vida misma, y no se puede negar; pero también se trata de algo necesario, pues está cargado de un enorme potencial capaz de transformación individual y social ${ }^{14}$. Por esta razón, el conflicto no se resuelve, sino se "regula", se transforma de la mejor manera ${ }^{15}$. De hecho, la transformación del conflicto en sentido positivo o negativo conllevaría manifestaciones de violencia y paz.

\footnotetext{
${ }^{11}$ Ibíd., 114-116.

${ }^{12}$ Ibíd., 131-132.

${ }^{13}$ Para comprender la relación entre las culturas, los conflictos y la paz, ver a Cano y Molina "Culturas, mundos globales y paz", 9-27.

${ }^{14}$ Jares, Educación y conflicto. Guía de educación para la convivencia, 17-36.

${ }^{15}$ Lederach, El abecé de la paz y los conflictos. Educación para la paz, 60.
} 


\section{Particularidades de la teoría de la violencia}

En coherencia con la teoría del conflicto no se debería asumir un concepto simple de "violencia", como el que se enfoca exclusivamente en acciones somáticas, corporales, sino que se hace preciso asumirlo de manera amplia, en conexión con la compleja realidad de la vida. Así, la violencia "está presente cuando los seres humanos se ven influidos de tal manera que sus realizaciones efectivas, somáticas y mentales están por debajo de sus realizaciones potenciales" ${ }^{\prime \prime}$.

De esta definición, fundada en la distancia entre lo potencial y lo efectivo, teniendo como causa la "influencia", se pueden identificar dos clases de violencia: la directa y la indirecta. La violencia indirecta se da cuando los conocimientos y recursos son monopolizados o mal utilizados, pues afectan desde el sistema a otras personas o contextos sociales; mientras, la violencia directa se presenta cuando los medios de realización son destruidos ${ }^{17}$.

$\mathrm{Al}$ adentrarse en las dimensiones de la violencia conviene identificar que la estructura básica de una influencia completa tendría como componentes los mismos que están presentes en cualquier proceso de relación y comunicación: (1) Alguien que influye. (2) Una influencia. (3) Un modo de influir. Otro modo de describirlo desde la violencia personal sería: (1) Un sujeto. (2) Un objeto. (3) Una acción. La particularidad se encuentra en la afectación, en la influencia; pero estas solo son las bases de muchas variaciones que se pueden establecer, así como versiones "truncadas", catalogadas como violencia aunque uno de sus componentes esté ausente.

Con este presupuesto, en primer lugar, puede hacerse una distinción básica entre violencia física, que puede ir desde la imposibilidad de movilizarse hasta la muerte como extremo, y la violencia psicológica, que incluye todo tipo de actitudes $\mathrm{y}$ expresiones que minimizan las potencialidades mentales ${ }^{18}$.

Al continuar con el ejercicio de clasificación, en segundo lugar, la violencia se diversifica en su influencia, ya se trate de un enfoque negativo o positivo, en la medida en que restrinja o las personas no puedan desplegar sus posibilidades.

En tercer lugar hay violencia incluso cuando no existe un objeto físico (violencia truncada). Por lo general se presenta como "amenaza" física o mental. En contrapartida, la destrucción directa de objetos es considerada un modo de violencia psicológica.

\footnotetext{
${ }^{16}$ Galtung, Sobre la paz, 30.

${ }^{17}$ Ibíd., 31-32.

${ }^{18}$ Ibíd., 33-34.
} 
En cuarto lugar se encuentra la dimensión que para Galtung resulta primordial: hay violencia directa o "personal" cuando hay claramente un sujeto, pero hay violencia indirecta o "estructural"19 cuando no hay un sujeto, pues consiste en manifestaciones de aquello que se ha llamado injusticia social.

En quinto lugar se distingue entre violencia deliberada y no deliberada, que da cuenta de la culpabilidad, la intención y las consecuencias.

En sexto lugar se puede identificar la violencia manifiesta, que generalmente es observable, y la violencia latente, que se evidencia en un ambiente de tensión o inestabilidad en el que la realización efectiva se ve amenazada ${ }^{20}$.

Desde este panorama se considera que la violencia personal es inestable, mientras que la violencia estructural pareciera tener mayor grado de estabilidad o permanencia. Para comprenderlas conviene reconocer los medios o maneras como se producen. Así, en estos tipos de violencia se puede distinguir el uso de una serie de herramientas y un estilo de organización ${ }^{21}$.

Al identificar una tipología de violencia estructural, se piensa directamente en la desigualdad como característica principal, que persiste en diversos cambios históricos y que está en relación directa con la estructura social y la estratificación. En dicha estructura social intervienen actores, sistemas, rangos y niveles, en complejas relaciones de poder que surgen de los individuos y sostienen o profundizan las desigualdades. Esta perspectiva conlleva a afirmar que la violencia personal está en relación con la dimensión estructural y la violencia estructural con la dimensión personal, en reciprocidad ${ }^{22}$.

De manera paralela conviene resaltar aquí el concepto de "violencia cultural", que aparece en las últimas obras de Galtung y adquiere reconocimiento en el ámbito de las investigaciones sobre paz y violencia. En esencia, esta termina legitimando la violencia directa-personal e indirecta-estructural, de manera intencionada o no intencionada, por medio de distintas manifestaciones simbólicas. "Se divide por su contenido (religión, derecho e ideología, lenguaje, arte, ciencias formales/empíricas, cosmología o cultura profunda) y por sus transmisores (escuelas, universidades, me-

\footnotetext{
${ }^{19}$ Galtung prefiere hablar de "estructural” por ser un concepto más abstracto que "institucional”.

${ }^{20}$ Galtung, Sobre la paz, 34-41.

${ }^{21}$ Ibíd., 43-47. Aquí Galtung diferencia con mayor detalle entre la violencia centrada en la anatomía personal (golpe, desgarramiento, incisión, quemadura, envenenamiento, evaporación) y la centrada en la fisiología (en cuanto negación del aire, agua, alimento y movimiento). Ibíd., 47.

${ }^{22}$ Ibíd., 48-63.
} 
dios de comunicación)"23 a a los que seguramente se podrían añadir otras tantas instituciones sociales.

\section{Las posibilidades desde la teoría de la paz}

La definición más básica o simple de paz consiste en reducción de la violencia o ausencia de guerra; pero -en concordancia con lo afirmado- también puede ser entendida como transformación creativa del conflicto sin violencia ${ }^{24}$. Por tanto, la paz ha de ser vista en todas sus posibilidades, en sus particularidades y en la multiplicidad de sus aristas. No es pertinente concebirla de manera unidireccional o limitada, sino de manera "compleja", como red de interrelaciones.

De este modo, la paz sería concebida al mismo tiempo como ausencia de violencia personal, llamada "paz negativa", y ausencia de violencia estructural, también conocida como "paz positiva" y asimilada como "justicia social". Se trata de una relación en doble dirección que constituye el amplio concepto de paz por el que aquí se apuesta en perspectiva integral ${ }^{25}$.

En cuanto a los estudios o investigaciones "sobre la paz" se pueden destacar tres grandes corrientes: (1) La investigación empírica, en la cual los datos son centrales y se contrastan con la teoría. (2) La investigación crítica, que compara los datos con los valores, y estos últimos se privilegian. (3) La investigación constructiva, que coteja la teoría con los valores, y nuevamente, en este caso, los valores son favorecidos. Aquí "los datos dividen el mundo entre lo percibido y lo no percibido, las teorías entre lo previsto [...] y lo imprevisto; y los valores dividen el mundo entre lo deseado y lo rechazado" ${ }^{26}$.

Al retomar la definición de la paz, nos encontramos con un sinnúmero de particularidades propias de los horizontes de comprensión de Oriente o de Occidente, en la riqueza que proviene de infinidad de culturas y tradiciones, donde hay una variación dinámica que va de lo externo (Occidente) a lo interno (Oriente).

Sin embargo, llama la atención que actualmente, en la mayor parte del mundo, el concepto predominante sea el de pax romana, ligada al "pacto", en un marco lega-

\footnotetext{
${ }^{23}$ Ídem, Paz por medios pacificos, 57.

${ }^{24}$ Ibíd., 31.

25 Ídem, Sobre la paz, 63-72.

${ }^{26}$ Ídem, Paz por medios pacificos, 33. Conviene resaltar que, para Galtung, los valores son los que hacen la diferencia en el conjunto de las ciencias de paz, pues sin valores simplemente se estaría realizando un estudio social o estudios particulares sobre el mundo, pero no sería una disciplina sui generis (ibíd., 36).
} 
lista, y entendida como "ausencia de guerra", que pareciera convenir esencialmente a quienes detentan el poder y están interesados en dar continuidad al statu quo de explotación, dinámica económica y dominio total, incluso fomentando, interviniendo o manipulando guerras ${ }^{27}$.

El cuestionamiento latente es si la humanidad está dispuesta a retomar el concepto paz, contando con las tradiciones religiosas y culturales conocidas, para dar una respuesta divergente a las hegemónicas. Desde estas tradiciones se pueden contar las siguientes visiones particulares, entre otras tantas, la siguiente:

De la prosperidad y la justicia de la shalom, del amor abnegado y omnicomprensivo de la agape [...] de la solidaridad y la compasión que se encuentran en el quran [...] de la armonía de la homonoia y la eirene, del "estado de espíritu bien templado" o la "paz mental" de shanti, p’ing ho y heiwa, del no hacer daño de los jainistas y la compasión de la ahimsa budista, por no mencionar la riqueza perceptiva desvelada y parcialmente realizada del satyagraha de Ghandi. ${ }^{28}$

Cada una de ellas está cargada de un caudal singular de costumbres, herencias e imaginarios, que han reflexionado y vivido la paz, así como un conjunto de valores próximos $^{29}$. Sin embargo, sería un error asumir de manera simplista solo una de estas visiones, igual que sería demasiado inocente creer que la combinación de todas estas perspectivas dará lugar a una sola concepción de paz, en una gran receta aceptada por todas las culturas, en donde la propia es relegada u opacada.

El reto que aquí se evidencia consiste en buscar un punto medio donde el concepto de paz, con una actitud crítica y propositiva, alejado de visiones unidireccionales o imposiciones, pero también con el condicionamiento del propio contexto, sea lo suficientemente dinámico y significativo para mantener relaciones efectivas de paz en el ámbito personal, interpersonal y estructural.

\section{Conflicto y posconflicto en Colombia}

$\mathrm{Al}$ traer a colación la realidad colombiana en relación con la teoría del conflicto descrita, se puede confirmar que no tendría nada de excepcional, en cuanto solo es una pequeña parte del complejo panorama mundial. Sin embargo, el contexto colom-

\footnotetext{
${ }^{27}$ Ídem, Sobre la paz, 73-99.

${ }^{28}$ Ibíd., 100-101.

${ }^{29}$ Para mayor conocimiento de la aplicación de valores cristianos en el contexto de la educación religiosa, ver a Díaz, "Las preocupaciones del profesor de religión", 301-318.
} 
biano se puede caracterizar por medio de distintas variables y factores, para luego ser traducidos creativamente, y así la sociedad colombiana se acerque al ideal que por ahora solo se proyecta en discursos y textos.

No obstante, más allá de la disputa entre lo global y lo local que aquí se refleja, interesa mostrar que los problemas o las dificultades que causan traumatismo a la sociedad en general y a los individuos en particular, se presentan cuando hay reacciones violentas que surgen de un mal manejo del conflicto, cuando no se atiende a la multitud de formas de violencia, igual que a las variadas formas de construcción de paz.

En Colombia hay un imaginario bastante difundido que asimila de manera inmediata el "conflicto" y el "posconflicto" al escenario de violencia que tiene como actores al Estado y a la sociedad civil, por un lado, en contra de los distintos grupos armados ilegales de izquierda (guerrillas), de derecha (paramilitares) o sin ideología política (bandas criminales), por otro.

Tal escenario, si se tiene en cuenta de manera radical la argumentación ya dada, no podría ser calificado de "conflicto"; más bien es ejemplo de violencia personal y estructural, claro está, con una larga y compleja historia. Si se prefiere, podría llamarse conflicto "armado", siempre con el adjetivo que aclare y facilite el matiz adecuado. Por la misma razón, no podría hacerse mención de un "pos", de un posconflicto en el ámbito colombiano, ya que el conflicto se transforma, permanece con nuevos rostros, pero nunca se supera del todo, ni se elimina o se deja a un lado.

Por supuesto, quienes reflexionan y trabajan sobre el conflicto colombiano hacen alusión al "posconflicto" para referirse a la etapa que sigue de manera inmediata a la firma de un acuerdo entre el Gobierno y alguno de los grupos ilegales armados, en cuyo caso convendría más el concepto "pos-acuerdo"; pero más allá de las diferencias entre las teorías y los conceptos empleados en Colombia, en vez de insistir en cambiar las denominaciones, pensar y hacer propuestas sobre este momento en particular, se debe reconocer que se trata de un claro signo de conciencia y responsabilidad de algunos sectores de la población, que merecen reconocimiento y se debieran multiplicar, a condición de que no hagan parte de estructuras perversas como manipulación de masas, campañas proselitistas de orden político o religioso, e incluso medios para generar lucro en organizaciones y personas particulares.

Las dificultades se profundizan y entran en una especie de aporías insalvables, cuando se promueven visiones cerradas:

...la visión más ingenua que se puede tener de un conflicto es creer que queda solucionado una vez que las élites de las partes de la conformación del conflicto 
han aceptado la solución, como lo muestran sus firmas en un documento que esboza la nueva estructura. ${ }^{30}$

La firma de un acuerdo, aunque sea un primer e importante paso para proporcionar soluciones contextuales y pueda traer distintos beneficios, claramente es insuficiente para instaurar la paz (en sentido amplio) en un país; no porque una de las partes o varias de ellas no sean honestas con el proceso y los compromisos que generalmente contraen, sino porque en un conflicto -como el colombiano- la paz "firmada", como ya ha sucedido en otros momentos, usualmente olvida incluir de manera explícita y sistemática a la población en general, a la mayoría de colombianos que no hace parte de grupos armados legales o ilegales.

A esto se añade que los acuerdos firmados, por lo general, no tienen en cuenta la transformación individual y de las estructuras sociales, para que todos aprendan a encauzar positivamente los conflictos. Por esta razón, más que proponer una solución que prescinda de las élites y promueva la salida de los conflictos exclusivamente con las fuerzas del pueblo, que sería otra posición extrema y simplista, es indispensable aunar esfuerzos en fórmulas que impliquen un doble carril (élites y pueblo) ${ }^{31}$ o múltiples carriles, no para justificar las divisiones sociales existentes, sino con el firme propósito de que todos los actores sociales puedan hacer aportes a la paz.

Desde esta faceta, más allá de las precisiones conceptuales que aquí se proponen y nacen de la teoría del conflicto (violencia y paz), tampoco sería pertinente satanizar o desprestigiar esta realidad particular que en Colombia se ha llamado conflicto y posconflicto, en especial porque ante el desgaste de varias décadas de guerra interna y un sinnúmero de problemáticas asociadas a esta grave situación, todo esfuerzo, intencionalidad o proyecto que favorezca la paz y la convivencia debe ser acogido y valorado en sus objetivos. Así, insistimos, la aclaración conceptual puede ubicar los discursos y las investigaciones de manera pertinente, pero no debe ser motivo de menosprecio hacia las acciones en pro de la paz.

Con el fin de entender con mayor exactitud lo que se vive en Colombia -y en esto coinciden las dinámicas de las ciencias de paz y la resolución de conflictos-, es preciso recurrir siempre a la memoria histórica.

[Desde la] independencia como nación en el siglo XIX padecimos diez guerras civiles, cuyos resultados, medidos en términos de dolor, sangre, desconfianza

\footnotetext{
${ }^{30}$ Galtung, Paz por medios pacíficos, 131.

${ }^{31}$ Ibíd., 131-132.
} 
y afectación de la economía, no pueden considerarse, desde la distancia que nos proporcionan los ańos, como justificadas por los motivos invocados para su realización. ${ }^{32}$

A esto se añade la Guerra de los Mil Días (entre el siglo XIX y el XX), una vergonzosa década denominada "la violencia" (en la mitad del siglo XX), el enfrentamiento directo y la muerte entre movimientos políticos, el nacimiento de las guerrillas, la aparición del narcotráfico, el surgimiento del paramilitarismo, así como toda suerte de bandas criminales y movimientos políticos corruptos.

Y ya que "la violencia tiene múltiples expresiones que no excluyen, pero sí sobrepasan la dimensión política" 33 (tanto así que la mayor cantidad de actos violentos y de víctimas se ocasionan por motivos no políticos ni de grandes grupos armados, sino de delincuencia común), lo que realmente se necesita es un enfoque mucho más amplio en el análisis y en la consecución de la paz.

Llegados a este punto se propone asumir el conflicto colombiano desde su complejidad, identificando con pericia y conciencia la mayor cantidad de actores, igual que de objetivos y proyectos fallidos que han dado lugar a un generalizado clima de frustración, pero también a la capacidad de soñar y a la voluntad de reconstruir el país. Porque solo de esta manera -si se cuenta con el conjunto de variables-será pertinente una concepción holística del conflicto y se pueden allanar nuevos caminos de solución; pero si insistimos en mantener visiones reducidas, no complejas, del conflicto, la transformación se traducirá en acciones incompletas, en desgaste sociohistórico y en incredulidad sobre la misma posibilidad de solucionar los conflictos por vía política, acuerdos firmados o procesos educativos.

Claro está que la solución de los conflictos está en íntima relación con la búsqueda de la "verdad" de lo sucedido, así como con procesos claros de justicia y reparación de las víctimas de la violencia. Con este propósito se han promovido comisiones de expertos; entre las más destacadas en cuanto a su impacto se encuentran las siguientes:

1. La Comisión Nacional Investigadora de las Causas y Situaciones Presentes de la Violencia en el Territorio Nacional, de 1958, que hizo énfasis en el asistencialismo social y la reconstrucción del país, pero no en identificar responsabilidades.

\footnotetext{
${ }^{32}$ Jaime, "El conflicto armado en Colombia”, 121.

${ }^{33}$ Sánchez (coord.), Comisión de estudios sobre la violencia. Colombia: violencia y democracia, 23.
} 
2. La Comisión de Estudios sobre la Violencia, de 1987, que realizó un diagnóstico en el cual se destacaron algunas tipologías sobre la violencia. Esta Comisión también hizo recomendaciones precisas para llevar a cabo negociaciones en conflictos armados y atender la seguridad urbana.

3. El Área de Memoria Histórica, MH, de la Comisión Nacional de Reparación y Reconciliación, CNRR, de 2007 a 2012, la cual -en el marco de la Ley de Justicia y Paz- se propuso reconstruir históricamente los relatos del terror de las víctimas ${ }^{34}$.

Como resultado, se han alcanzado logros que han favorecido la recuperación de la memoria histórica, se han presentado diagnósticos del Estado colombiano y su compleja transformación, se han redactado documentos muy valiosos con lecturas diferenciadas, y también han surgido propuestas de paz desde distintos ámbitos.

Por consiguiente, compartimos - con John Paul Lederach-que el problema no consiste en ausencia de propuestas de paz, sino en la incapacidad que hemos mostrado los colombianos para trabajar unidos, para aunar esfuerzos, para escuchar las propuestas de paz de los otros grupos, partidos, movimientos y con valentía poder integrarlos en una estrategia que supere la evidente fragmentación social y logre mayor impacto ${ }^{35}$.

De aquí recobra importancia algo tan obvio que, por lo mismo, tiende a ser olvidado: la necesidad que tenemos de aprender a "dialogar", de hacer del diálogo una herramienta primordial de reconstrucción o fortalecimiento del país. Con el diálogo podremos entender con mayor facilidad que el conflicto colombiano tiene muchas aristas, gran cantidad de puntos de vista, tantos como grupos o personas conforman el país.

Al mismo tiempo, el diálogo cuestiona los lugares seguros, los discursos aprendidos y enseña a escuchar las percepciones y argumentos de los demás, más allá de un acuerdo por conveniencia política o por cansancio/desgaste, en el cual se justifiquen las distancias. Sobre este punto vale la pena rescatar una serie de pensamientos del filósofo Estanislao Zuleta:

El diálogo actualmente, en todos los niveles, es una condición de supervivencia. El diálogo tiene que ser en alguna medida racional, es decir, prestarse a la argumentación. Tenemos que estar dispuestos a sustentar por medio de argumentos las propias posiciones y estar dispuestos a oír los argumentos del otro. Si uno no está dispuesto a eso puede hacer pactos de no agresión, por

\footnotetext{
${ }^{34}$ Jaramillo, "Expertos y comisiones de estudio sobre la violencia en Colombia", 234-237.

${ }^{35}$ Lederach, "Experto internacional, habla sobre la reconciliación en Colombia".
} 
comodidad, pero no establece diálogo [...]. Es imposible que nos sometamos a una sola idea sin caer en el terror absoluto. ${ }^{36}$

Lo meritorio de aprender a dialogar no solo se encuentra -para este filósofo colombiano- en los resultados proyectados y en los acuerdos firmados, sino en la serie de valores y capacidades humanas, como son el amor, la reflexión, el respeto a la pluralidad de manifestaciones y opciones, igual que a formas de gobierno que de manera efectiva promuevan la paz:

El amor y el pensamiento representan el límite infranqueable de la libertad. El fracaso absoluto de cualquier tirano está exactamente en ese límite donde el hombre piensa, desea y ama [...]. Aprender a amar la pluralidad es algo realmente difícil. Estamos acostumbrados a creer en nuestra idea como la única verdadera, no cuestionable ni enriquecible; a declarar herejes, revisionistas o cualquier otra cosa al que difiera de nuestra idea; a pensar en términos de buenos y malos; a organizar partidos fanáticos que producen naturalmente, como el hígado la bilis, sus ortodoxos y sus herejes. ${ }^{37}$

No es cosa fácil combatir el dogmatismo. Ante todo porque nadie se considera a sí mismo dogmático, sino solamente defensor intransigente de una verdad o de la pureza de alguna gloriosa tradición. Es como la opresión: nadie se considera un opresor sino tan solo guardián del orden e incluso protector de aquellos cuyos excesos es preciso evitar. ${ }^{38}$

Una democracia participativa es el único remedio para los males que vive Colombia. Un pueblo fuerte, organizado, capaz de reivindicar sus derechos, de reclamar sus necesidades, es el único que puede remediar la trágica debilidad del Estado. Esperemos que de tanta sangre, de tanto sacrificio inútil, resulte al fin la clara voluntad de luchar por una sociedad justa y democrática. ${ }^{39}$

Finalmente, sin negar la imperiosa necesidad de reparación y justicia, y sin querer minimizar el sufrimiento de las "víctimas" directas de la violencia, se debe reconocer que cada colombiano también es víctima de una u otra manera. Esta afirmación no surge por un sentimentalismo vacío o por un simple afán de reconocimiento, sino se sustenta en la perspectiva estructural y cultural de la violencia porque, al hacer parte del sistema, de la sociedad colombiana, sus acciones y pensamientos han estado influen-

\footnotetext{
${ }^{36}$ Zuleta, Colombia: violencia, democracia y derechos humanos, 19.

${ }^{37}$ Ibíd., 20.

${ }^{38}$ Ibíd., 56.

${ }^{39}$ Ibíd., 93.
} 
ciados por múltiples violencias activas y latentes. Y, claro está, cada colombiano sería tanto víctima como "victimario", pues también ha sido agente de violencia personal y estructural en mayor o menor medida.

Desde este punto de vista, el acto egoísta de corrupción de quien busca sacar ventaja de la situación, el silencio cómplice, la intransigencia, la intolerancia, la acción agresiva y manipuladora del político, del empresario, pero también del docente, del líder religioso, del familiar más cercano o más lejano, del compañero de trabajo o de estudio, del vecino, es tan fatal, tan catastrófica (en términos de consecuencias estructurales y culturales, vistas como un engranaje) como las atrocidades cometidas por grupos armados ilegales, sin querer minimizar su impacto, porque dichas acciones -precisamente por ser parte del mismo sistema estructural- tienen secuelas palpables y subsecuentes sobre el resto de la población, sobre las millones de historias que diariamente se escriben y no siempre son "noticia" en los diversos medios informativos.

\section{El compromiso educativo y religioso por la paz}

$\mathrm{Al}$ retomar cuidadosamente los argumentos esbozados, resulta evidente el alto grado de responsabilidad que tienen todas las instituciones de educación, en todos los niveles, sobre el estado actual de violencia que vive el país; y por supuesto, esta responsabilidad también es compartida por las religiones, las iglesias y los movimientos de orden espiritual que hacen presencia en el país. Es hora de reconocer las responsabilidades compartidas y presentar escenarios de encuentro que hagan posible una cultura de paz.

\section{El ámbito educativo en general y la educación para la paz}

Reconocer la responsabilidad de la educación en la ausencia de paz y las manifestaciones de violencia no significa hacerla causante única; aunque sí conviene entrar a cuestionar permanentemente si los métodos, enfoques y propuestas académico-pedagógicas contribuyen o no a construir un país menos violento, más unido y consciente de su deber.

En este contexto se retoman las potencialidades presentes en la "educación para la paz". Tal propuesta no consiste en un bloque aislado, pues debe estar en relación con la "investigación sobre la paz" y las "acciones de paz". Estos son tres pilares esenciales, pero han estado desunidos, porque en la práctica no hay conciencia ni voluntad de unirlos. En parte se debe a que, históricamente, las universidades no acogieron -de manera inicial- las investigaciones sobre y para la paz, y estas fueron asumidas por otro tipo de instituciones; también se debe a que la educación ha estado influenciada por grupos de élites que no tienen interés en los argumentos venidos de la paz, precisamente 
cuando estos llegan a cuestionar su poder e influencia. El resultado es la ausencia generalizada de propuestas estructuradas y consistentes en educación para la paz ${ }^{40}$.

El desafío y los cuestionamientos se dirigen a la educación misma, es decir, a la manera como estamos educando, en muchas ocasiones, en complicidad con la violencia directa y estructural, reproduciendo o justificando acciones agresivas, no solo por acciones directas sino por formas o esquemas generalizados que luego se reproducen fuera de los espacios educativos.

Como consecuencia, valdría la pena cuestionar fuertemente la educación actual desde el prisma de la paz: “¿Permite una retroalimentación? ¿ Tiende a unir a la gente en una empresa en común o a mantenerla separada? ¿Permite la participación general? ¿La forma total de la educación posibilita un cambio autogenerado? En suma, ¿en la educación hay diálogo y no solo mensaje?"¹ .

Estos cuestionamientos sobre la forma de educar se pueden ampliar a la idea de que exista formación concreta sobre paz, como asignatura en los centros educativos, tal como sucede con la Ley 1732 de 2014, que promueve la "cátedra de la paz"42 en Colombia, como obligatoria para colegios y con mayor libertad en relación con universidades. Esta manifestación oficial del Estado, más allá de la buena intención de sus creadores y de los intereses gubernamentales, corre el riesgo de convertirse en una simple cortina de humo que oculte la falta de compromiso real por la transformación sistemática y estructural del país. Esto lo expresa Galtung al afirmar que "el resultado sería servir de coartada: la sociedad ha hecho algo por la 'paz', ya que la 'paz' figura entre las materias de clase” ${ }^{` 3}$, y por consiguiente, no hay nada más que se pueda hacer; la tarea está cumplida, aunque la injusticia social permanezca.

No por esto puede desestimarse la educación para la paz. Al contrario, se hace indispensable conocerla a profundidad, teniendo presente que posee una prolongada historia, que Xesús Jares identifica en cuatro grandes olas:

- La primera se dio con la llamada "Escuela nueva" del siglo XIX, como respuesta a la ineficacia de la escuela tradicional, donde se criticaba la militarización de la escuela y la falta de formación de sentido crítico, aunque solo luego de la Primera Guerra Mundial tomó más fuerza su postura radical por la paz.

\footnotetext{
${ }^{40}$ Galtung, Sobre la paz, 133.

${ }^{41}$ Ibíd., 136.

${ }^{42}$ República de Colombia, "Ley 1732 de 2014".

${ }^{43}$ Galtung, Sobre la paz, 137. Es llamativo que esta preocupación, escrita hace veinte ańos en forma de denuncia sobre un peligro latente, tenga tal vigencia en el actual contexto colombiano.
} 
- $\quad$ La segunda ola se generó por la Segunda Guerra Mundial, desde la perspectiva de la ONU y la Unesco, con el propósito de generar y consolidar una educación para la paz, en solidaridad, respeto, cumplimiento de los derechos humanos e interdependencia internacional.

- La tercera ola se identificó con la noviolencia como bandera principal y, por tanto, se fundó especialmente en el pensamiento y la vida de Ghandi (aunque hay otros representantes e instituciones que también la impulsan). Se caracteriza por promover la firmeza de la verdad y acciones no violentas pero efectivas.

- La cuarta ola se dio mediante la investigación para la paz (peace research), por medio de revistas especializadas e instituciones que, gracias a desarrollos teóricos buscan mediar en la transformación de la realidad de la guerra hacia un mundo desarrollado y en $\mathrm{paz}^{44}$.

Así mismo, Jares considera que la propuesta de educación para la paz debe estar configurada como respuesta directa a un contexto convulsionado, determinado por la globalización neoliberal, la guerra preventiva y distintas formas de terrorismo. Ante este diagnóstico, configurado desde la mirada occidental, se proponen seis objetivos y contenidos que podrían estar presentes en todas las instituciones de educación:

(1) Enfatizar el valor de la vida humana y la dignidad de todas las personas, lo que implica fomentar la cultura de la noviolencia, de la paz y la solidaridad. (2) Fomentar el compromiso con la búsqueda de la verdad. (3) Sensibilizar sobre el valor de la justicia y el rechazo de la venganza y el odio. (4) Combatir el miedo y la desconfianza. (5) Insistir en el valor de la democracia, la paz y la necesidad de globalizar los derechos humanos. (6) Educar en el valor del compromiso y la esperanza ${ }^{45}$.

A cada uno de estos componentes Jares propone una serie de objetos específicos por medio de los cuales se pueden hacer más evidentes estos valores para la paz. Con todo, opta por profundizar en el segundo y el sexto, en la verdad y la esperanza como pilares esenciales de su propuesta:

- Educar en la "verdad", como respuesta a las problemáticas que genera el poder de los medios de comunicación y la manipulación regular de la información,

${ }^{44}$ Jares, Educación para la paz. Su teoría y su práctica, 27-109. Asumimos la palabra "noviolencia" retomando los argumentos de Jares, pues es más que una simple negación (no violencia o no-violencia), ya que conlleva una visión dinámica (ibíd., 87).

${ }_{45}^{4}$ Ídem. Educar para la verdad y la esperanza. En tiempos de globalización, guerra preventiva y terrorismos, 125-127. 
pero también debido a que la mentira se ha convertido en una estrategia política normalizada o común a sus dinámicas internas.

- Educar en la "esperanza", para combatir la ideología del neoliberalismo que se presenta como la última e ineludible etapa de la humanidad, así como aminorar la lucha individualista alejada de un compromiso comunitario y político. También se debe educar en la esperanza ante la "normalización" de la guerra, la violencia y el miedo ante los conflictos, para generar la capacidad de vislumbrar otros caminos ${ }^{46}$.

$\mathrm{Al}$ intentar reconducir este bagaje histórico conceptual y práctico hacia el ámbito colombiano, se destaca una serie de iniciativas de distinta índole en búsqueda de la creación, gestión y consolidación de una educación para la paz, en especial desde la década de los años 80, con el fin de formar líderes o promotores de paz, no en el marco oficial educativo, sino particularmente desde otro tipo de organizaciones, como las no gubernamentales ${ }^{47}$.

Igualmente sobresalen distintos esfuerzos por responder a procesos de reinserción en la década de los años 90, mediante la integración de desmovilizados en la vida civil, el ofrecimiento de planes de formación en primaria y secundaria que se acomodaran a su realidad, entre otras actividades y propuestas que no han tenido mucha difusión o que parecieran no ser recordados. Con esto se muestra, en parte, que las olas mencionadas por Jares también han hecho parte de la historia de la educación para la paz en Colombia, pero con algunas particularidades.

Además se deben destacar las iniciativas teóricas y prácticas de distintas universidades en todo el país, en especial, en las últimas décadas, que han tenido presente el conflicto colombiano en todas sus dimensiones y no solo han promovido y financiado proyectos de investigación, sino también proyectos de intervención social. En este escenario emerge como correlato el Acuerdo por lo Superior 2034. Propuesta de politica pública para la excelencia de la educación superior en Colombia en el escenario de la paz, documento creado por el Consejo Nacional de Educación Superior, CESU, donde se proyecta a veinte años una visión de "sociedad en paz (justa, culta, democrática, solidaria, próspera, competitiva e incluyente), en la que convivan digna y pacíficamente ciudadanos libres, éticos, responsables y productivos”48.

\footnotetext{
${ }^{46}$ Ibíd.

${ }^{47}$ Observatorio para la Paz, “¿Quiénes somos?”.

${ }^{48}$ Consejo Nacional de Educación Superior, Acuerdo por lo Superior 2034. Propuesta de política pública para la excelencia de la educación superior en Colombia en el escenario de la paz.
} 
El futuro de documentos de esta clase, que inicialmente parecieran tan ideales o inalcanzables, se cristalizaría si se transformara la actual voluntad política, si se incluyera un mayor número de actores, si se asumiera en perspectiva inter y transdisciplinar ${ }^{49}$, si se consolidara una clara conciencia del compromiso universitario por la construcción de una sociedad justa, una sociedad en paz.

\section{La religión ante la violencia y la paz}

No se puede ocultar que para algunos especialistas en teoría de la paz, líderes y gestores de paz, así como para promotores o expertos en resolución de conflictos, la dimensión religiosa no tiene importancia en este tipo de procesos, carece de valor, les es indiferente o la consideran tan solo un imaginario que no impacta la vida diaria, la vida real, el ámbito público y, por lo mismo, no reconocen su tradición en temas de paz ni su futura presencia. No obstante, al retomar a Galtung, la paz tiene "resonancias religiosas, y es probable que ello contribuya a la utilización de la palabra 'paz' como portadora de sentimientos de amor y hermandad universales en nuestros días" ${ }^{\prime 50}$.

Sin embargo, este reconocimiento sobre la paz y su relación con la tradición religiosa presupone un concepto de religión que no se limita a una visión institucionalizada, a una estructura cerrada, petrificada o desencarnada de la profundidad humana, sino que remite a una re-ligare (unión), re-legere (interpretación) o re-elegire (opción) que nos han brindado los estudios de la ciencias de las religiones, entre ellas la filosofía ${ }^{51}$ y la teología ${ }^{52}$, así como el testimonio de infinidad de creyentes y comunidades de fe que han vivido coherentemente lo que han profesado.

La relación entre la religión y el conflicto está marcada por la cultura en donde nace o se desarrolla; y el contexto cultural determina la manera de pensar y el comportamiento de quienes hacen parte del conflicto, ya se trate de un conflicto personal o estructural, incluidos conflictos que explícitamente tienen un componente religioso.

Así, a manera de ejemplo, hay diferencias marcadas en la forma de asumir un conflicto, según se encuentre una persona o grupo en la civilización oriental u oc-

\footnotetext{
${ }^{49}$ Bonilla, Educación religiosa escolar en perspectiva de complejidad.

${ }^{50}$ Galtung, Sobre la paz, 69.

${ }^{51}$ Para un ejemplo del aporte de la filosofía a la paz, ver a Comins y París, "Epistemologías para el humanismo desde la filosofía para la paz", 5-11.

52 Para un ejemplo del aporte de la teología a la paz, ver a Angélico, "Humanismos, plataformas para la paz. Una lectura desde la teología trinitaria", 433-443; y para tener en cuenta la necesaria crítica ante los peligros de tergiversar esta teología, ver a Vilanova, "Una manipulación de la teología de la paz: las cruzadas medievales", 169-173.
} 
cidental, ya sea desde la tradición cristiana, en comparación con la tradición budista, que conciben de manera diversa el tiempo: el primero de manera finita (nacimiento y fin) y el segundo de manera infinita. Con ese mismo marco de concepción temporal será asumido cada conflicto (finito o infinito).

Conflicto individualizado en tiempo finito frente a conflicto colectivizado en tiempo infinito son puntos de partida muy diferentes para la teoría del conflicto y su práctica. La primera imagen se presta epistemológicamente al atomismo occidental, a una conflictología generalizadora, con una formación de teorías de tipo deductivo, posiblemente basada en una tipología de actores. La segunda imagen se presta a la dialéctica de la globalidad oriental, con una conflictología ideográfica, en la que hay una humanidad o forma de vida conectada. ${ }^{53}$

De manera paralela, mientras el cristianismo hace énfasis en la responsabilidad individual (unidad ética), que luego tiene consecuencias en la comunidad, y el budismo insiste en la responsabilidad colectiva como su unidad ética, del mismo modo cada tradición va a diferir en su concepción del conflicto ${ }^{54}$.

Estas afirmaciones no solo reflejan las evidentes relaciones entre paz y conflicto con las tradiciones religiosas, a quienes se deben imaginarios y conceptos. También es evidente la clara diferencia entre las tradiciones religiosas, aunque compartan algunos elementos, como un ejemplo de la pluralidad de experiencias que hay en el mundo y que se hace imposible ocultar o pasar de manera inadvertida ${ }^{55}$. Por tanto, en este contexto, resultan difícilmente coherentes y sostenibles muchas de las críticas dirigidas a "la religión", si no se tienen en cuenta sus diferencias, sus distancias y puntos de encuentro.

Otro asunto distinto ha sido el modo como estas tradiciones se han transformado, por lo general, de la mano de un prolongado proceso de secularización, hasta llegar a una mutación y recomposición ${ }^{56}$ que se refleja en andamiajes legales ${ }^{57}$, culturales, políticos y económicos.

\footnotetext{
${ }^{33}$ Galtung, Paz por medios pacificos, 122.

${ }^{54}$ Ibíd., 121-122. Por supuesto, aquí se trata de un ejemplo que toma en cuenta solo una perspectiva genérica y no las particularidades de la teología de cada tradición, que darían lugar a matices de otro orden, con otras lecturas éticas para este caso.

55 Sánchez Hernández, "Reconocimiento de la pluralidad. El desafío de la relatividad en los discursos teológicos", 65-79.

${ }^{56}$ González (ed.), Diversidad y dinámicas del cristianismo en América Latina; Grupo Interdisciplinar de Sociedad, Religión y Política, Diversidad y dinámicas del cristianismo en América Latina. Memorias del II Congreso Internacional; Ídem, Mirada pluridisciplinar al hecho religioso en Colombia: avances de investigación.

${ }^{57}$ Galtung, Paz por medios pacificos, 126.
} 
En cuanto a la relación entre la religión y la paz, esta pasa por la mediación de la transformación social, pues las experiencias religiosas perviven más allá de los ataques de movimientos secularistas y de algunas arremetidas de la modernidad que pretendían liberarse de "Dios, de la Iglesia o de la religión a la hora de definir cómo ha de funcionar la sociedad, cómo ha de ser interpretado el universo de las cosas y desde qué ideas debe orientarse el hombre en su vida. [Decían]: esta tarea la tiene que cumplir la simple razón" 58 .

No obstante, el triunfo de la razón ha sido cuestionado, especialmente debido al fracaso de la humanidad manifestado en las dos guerras mundiales, sin desconocer la manipulación o el impulso religioso del totalitarismo ${ }^{59}$.

Por esto mismo, no conviene negar las pertinentes críticas sobre las religiones, sus instituciones y expresiones, el lado oscuro de las experiencias religiosas que ha dado lugar a su rechazo, pues muchas han sido malinterpretadas y usadas con fines egoístas y mezquinos, para justificar el odio, la guerra, la muerte, en complejas expresiones fundamentalistas ${ }^{60}$. Son incontables los ejemplos a lo largo de la historia de la humanidad.

De manera singular, en Colombia también se encuentran bastantes muestras, desde las guerras de indígenas, pasando por el proceso de conquista y de colonia, hasta la constitución del Estado. En estas circunstancias históricas, la religión jugó un papel preponderante cuando en algunos momentos justificó la discriminación y la muerte o -también es necesario reconocerlo- en otros momentos defendió la causa de los más desprotegidos al igual que difundió valores de paz ${ }^{61}$.

Ciertamente, el mismo Galtung ubica la religión como parte de los contenidos que provocan la violencia "cultural". Además de confirmar esta clasificación, asistimos constantemente a diversas manifestaciones de violencia, tanto directa-personal como indirecta-estructural, que tienen como origen o como fin el ámbito religioso. Este tipo de violencias generalmente provienen de la concepción de un Dios trascendente, totalmente otro, alejado de la realidad y la historia humana.

\footnotetext{
${ }^{58}$ Muntaner, "La religión en la filosofía contemporánea", 299. De manera consciente preferimos no mencionar en el texto la palabra posmodernidad, para evitar el abuso que Hans Küng denunciaba hace más de dos décadas, y debido a la variedad de sus interpretaciones (Küng, Teología para la posmodernidad. Fundamentación ecuménica).

${ }^{59}$ Arendt, Los orígenes del totalitarismo.

${ }^{60}$ Tamayo, Fundamentalismo y diálogo de religiones.

${ }^{61}$ Arboleda, Pluralismo, tolerancia y religión en Colombia; Ídem, Guerra y religión en Colombia.
} 
La lista de consecuencias sería interminable, pero más que profundizar en los problemas evidentes, se quiere resaltar que también poseen un profundo pozo de significados y potencialidades que provienen de la dimensión religiosa, en la dinámica recursiva de lo inmanente y lo trascendente. Así, ante la innegable violencia cultural, se cuenta con la posibilidad de dar respuesta contextual desde la paz cultural, de la que es capaz la religión, en la vivencia profunda de sus valores y experiencias significativas.

De otra parte, es necesario recordar que el contexto latinoamericano tiene un panorama religioso particular, pues se diferencia de los demás continentes y regiones debido a que la transformación religiosa se ha centrado en una mayoría de cristianismos, donde la Iglesia Católica sigue siendo hegemónica, aunque progresivamente desciende el porcentaje de creyentes e influencia, para dar lugar a gran cantidad de iglesias, movimientos y grupos cristianos ${ }^{62}$.

En el entramado religioso de esta región también se deben contar las comunidades indígenas ancestrales, las religiones afroamericanas, el surgimiento o consolidación de otras religiones (especialmente orientales) y un buen número de ateos o indiferentes religiosos.

Las prácticas religiosas se muestran particularmente vivaces en América Latina y, contrariamente a Europa, las organizaciones religiosas no están en declive. Es posible también constatar su crecimiento significativo que señalan los subsecretariados de cultos de los diferentes países de la región. Se registran decenas de sociedades religiosas distintas al lado de la institución católica dominante. ${ }^{63}$

Un panorama tan variado, que tiene por particularidad la misma pluralidad de tradiciones y manifestaciones, lleva a confirmar la necesidad de asumir esta realidad como riqueza y nunca más como peligro o amenaza. Para cimentar esta interpretación se puede acudir a la teología del pluralismo religioso, que desde su configuración con-

\footnotetext{
${ }^{62}$ Como ejemplo de esta afirmación se puede ver a Mallimaci (dir.), "Primera encuesta sobre creencias y actitudes religiosas en Argentina (agosto de 2008)"; y en el caso de Bogotá, ver a Grupo Interdisciplinario de Estudios sobre Religión, Sociedad y Política, Giersp, "Encuesta de permanencia y cambios de la identidad política y religiosa en Bogotá”, 209-274.

${ }^{63}$ Bastian, "Las dinámicas contemporáneas de pluralización del campo religioso en América Latina”, 17. Esto mismo lo expresa Manuel Marzal: "En efecto, en esta tierra encantada conviven hoy, junto a la Iglesia Católica omnipresente, que es fruto de la profunda evangelización hecha por los países ibéricos, viejas religiones autóctonas en regiones poco accesibles, religiones sincréticas de origen americano, africano o asiático, el protestantismo trasplantado por los emigrantes de Europa o Estados Unidos, el pluriforme evangelismo fruto del proselitismo intenso de las últimas décadas y no pocos grupos eclécticos, producto del supermercado religioso del mundo posmoderno" (Marzal, Tierra encantada. Tratado de antropología religiosa de América Latina, 11).
} 
sidera la diversidad religiosa como el escenario desde el que urge vivir a profundidad la propia experiencia.

Así, las diversas manifestaciones no son condenadas, sino estimadas como oportunidad o caudal formativo de valores religiosos que construye una sociedad que puede vivir en paz. De esta manera, dicha teología no pretende construir una gran religión que acabe con las existentes, pero tampoco justifica las disputas agresivas entre ellas, configurando así la unidad de la humanidad en la diversidad.

Con ello se presenta un radical cambio de perspectiva, en cuanto las religiones e iglesias son percibidas en su potencial constructivo y relacional, no destructivo ni de división, para la cual deben liberarse de pretensiones absolutistas, colonialistas e impositivas, históricamente presentes. Así, se transforma el mismo imaginario de "unidad" que había prevalecido por muchos siglos en el cristianismo, ya que no se circunscribe al ámbito de la uniformidad o unidireccionalidad, para dar paso ahora a la pluralidad (que no significa pérdida de la propia identidad), de donde brotarían actitudes dialogales, respetuosas y comprensivas con la diferencia, en consonancia con las actitudes de paz.

Por consiguiente, el diálogo interreligioso y ecuménico, además de las reflexiones teológicas que surgen de este impulso ${ }^{64}$, se constituye en un amplio camino de resolución de conflictos, pues se encauza esta energía para lograr una mejor convivencia, que incluso puede potencializarse si todas las religiones, iglesias y movimientos de índole religioso trabajan unidas por el proyecto común.

Para retomar el ámbito colombiano, se han llevado a cabo distintos encuentros entre las religiones e iglesias, no solo para promover el diálogo interreligioso y ecuménico, sino también para orar juntos por la paz y para hacer explícito que la paz es un objetivo compartido, que permite ir más allá de las diferencias religiosas. Uno de los más recientes eventos fue la firma de una carta, por parte de 26 líderes religiosos y espirituales del país, en la que manifiestan el rechazo a las armas y su apoyo a la paz. Esta carta, titulada "Las armas son el fracaso de la palabra", hace un llamado a considerar la vida como sagrada y promover la dignidad humana, así como el perdón como esencial para vivir en paz $^{65}$.

${ }^{64}$ El conjunto de propuestas que surgen de la teología del pluralismo religioso es demasiado amplio para abordarlo en este espacio, por lo que solo se referencian algunos autores básicos: Dupuis, Jesucristo al encuentro de las religiones; Ídem, Hacia una teología cristiana del pluralismo religioso; Torres Queiruga, Diálogo de las religiones y autocomprensión cristiana; Knitter, Introducción a las teologias de las religiones; Bonilla, "Teología del pluralismo religioso: paradigma y frontera", 75-104.

${ }^{65}$ Reconciliación Colombia, "Las armas son el fracaso de la palabra". 
Y si trabajar por la paz no es, de por sí, tarea sencilla, tampoco lo es hacerlo mediante la conjunción de distintas tradiciones religiosas. Para ello se necesita preparar el terreno, superando los prejuicios y prevenciones. Allí puede intervenir la reflexión teológica crítica y contextual.

De esta forma, se facilitaría el objetivo de aprender a trabajar juntos, deponiendo los afanes de protagonismo y de dominio, en espíritu de veracidad, e incluir tanto a los líderes religiosos como al conjunto de creyentes, en una visión integral de la paz y con acciones mediadoras solidarias ${ }^{66}$, que en Colombia efectivamente se han realizado, pues distintas organizaciones religiosas han acompañado los procesos de paz, de desarme, de inclusión de desmovilizados a la sociedad y de formación para la paz, especialmente la Iglesia Católica.

\section{A manera de conclusión: el desafío de la educación religiosa para la paz ${ }^{67}$}

Igual que pasa con la religión en general, en distintos contextos parecerá extraño que la educación religiosa, además de tener algo que decir sobre la paz, sea parte integral de sus objetivos formativos. Más allá de que solo sea una temática presente en los libros o guías ofrecidos por las distintas editoriales, ciertamente la paz es componente vital de las tradiciones religiosas y, por tanto, debe serlo en los espacios que socialmente se tienen considerados para formar en esta dimensión religiosa, tanto en el ámbito de formación básica y secundaria, como en el nivel de educación superior, con sus respectivas particularidades.

Surgirá entonces el interrogante por el concepto de paz que deberían asumir las religiones. Sin renunciar a las tradiciones que configuran la identidad del creyente, las ciencias de la paz enseñan a no reducir la paz a la simple ausencia de conflicto armado. Por consiguiente, se necesita una noción de paz personal, estructural y cultural, que rechace abiertamente cualquier influencia o mediación violenta, pero también que rehúse todas las dinámicas y estructuras que promueven o permiten las distintas formas de injusticia social, para optar finalmente por una concepción cultural en favor

\footnotetext{
${ }^{66}$ Salazar, "Retos de la cooperación interreligiosa en Colombia en favor de la paz".

${ }^{67}$ En los últimos años, en Colombia se ha generado una amplia reflexión sobre la educación religiosa escolar, entre los que se destacan los siguientes libros: Meza (dir.), Educación religiosa escolar. Naturaleza, fundamentos y perspectivas; Meza y Suárez (eds.), Educar para la libertad. Una propuesta de educación religiosa escolar en perspectiva liberadora; Bonilla, Educación religiosa escolar en perspectiva de complejidad; Bonilla (ed.). Educación y religión: violencia y paz. Acercamiento al estado actual en diversos contextos.
} 
de la paz que fomente con claridad y pertinencia la noviolencia, desde los centros de educación y desde las comunidades de fe, hasta el punto de convertirse en germen (en doble vía) de estrategias de resolución-transformación de conflictos, desde el ámbito intrapersonal e interpersonal.

También hemos reconocido que la propia experiencia religiosa entra en conflicto con un contexto neoliberal globalizado, secularizado y tendiente a la violencia. Este conflicto se da cuando dicho contexto (que fomentan especialmente los medios de comunicación y las visiones exclusivistas económicas-empresariales) va en contravía de las enseñanzas que provienen de las tradiciones religiosas. La tarea consistirá en potencializar el conflicto para hallar caminos viables donde las tecnologías y la búsqueda del bienestar no contradigan la formación integral, siempre estando presente la dimensión religiosa como capital religioso que ofrece sentido de vida ${ }^{68}$.

En la misma ruta, la teología podría potenciar los desarrollos, teorías y acciones que han surgido del diálogo interreligioso y ecuménico (teología de la acción y teología del pluralismo religioso), para que las investigaciones realizadas se tornen hacia el camino de paz, vayan más allá del ámbito teórico y propongan nuevos senderos de encuentro efectivo, en un movimiento teológico perlocutivo que desate las reservas de la $\mathrm{fe}^{69}$.

Así, la paz no solo sería la meta, el final de un largo camino, sino el camino mismo constituido en teorías, acciones y actitudes de la vida diaria, especialmente en el buen ejemplo que pueden dar dos o más creyentes o instituciones, quienes a pesar de sus claras diferencias son capaces de entrar en diálogo sincero, cercano, fraterno y propositivo ${ }^{70}$. Se trata, por tanto, de un diálogo de paz desde el testimonio; y este puede tener mayores impactos pedagógicos que muchos de los enfoques existentes.

Claro está que el contexto de la educación religiosa y la formación para la paz -igual que el escenario colombiano- son complejos debido a las variables, a las redes que se tejen desde distintas aristas. Por lo mismo, hay numerosas opciones de solución o de propuestas que hagan efectiva la transformación social; y ahí, tanto la religión como la educación religiosa deben incrementar su injerencia, no para generar nuevos espacios de dominio o recuperar los feudos del pasado que se perdieron, sino para prestar un servicio a la humanidad, impulsados por la misma experiencia religiosa.

\footnotetext{
${ }^{68}$ En el intento por retomar la relación fe y razón, como fundamento de la pregunta por el sentido de la vida, ver a Bravo, "La pregunta por el sentido de la vida: la articulación esencial entre razón y fe", 643-668.

${ }^{69}$ Parra, "De camino a la teología de la acción", 166.

${ }^{70}$ Concilio Vaticano II, Constitución pastoral Gaudium et spes No. 34.
} 
También es indispensable, por tanto, aprender de la visión del pensamiento complejo, abriéndose al encuentro inter y transdisciplinar, sin olvidar "el tejido de eventos, acciones, interacciones, retroacciones, determinaciones, azares, que constituyen nuestro mundo fenoménico" ${ }^{11}$. Por ello, la formación en la dimensión religiosa no puede dar la espalda al conjunto de las demás ciencias, sino que debe apoyarse en sus investigaciones, metodologías y resultados. Es necesario perder el miedo a entrar en diálogo y, muy seguramente, a trasformar la realidad a partir de los conflictos que surjan de estos encuentros ${ }^{72}$.

Desde este horizonte, en Colombia se puede aprender de otras experiencias y de otras miradas, con la ayuda de quienes ya han recorrido caminos similares, como se encuentra en la "Matriz de acuerdos de paz" (Peace Accords Matrix), herramienta con 34 exitosos acuerdos de paz de todo el mundo, totalmente sistematizados, desde la que se puede retomar experiencias efectivas de distintos conflictos internos armados ${ }^{73}$. Esta investigación sistemática podría convertirse en insumo fundamental en la formación de resolución de conflictos, al apoyarse en lo que los valores de las tradiciones religiosas puedan aportar o reforzar.

En cuanto al ámbito colombiano, otras formas de responder a la urgencia de una cultura de paz se pueden delinear desde dos caminos. El primero es en el diálogo ecuménico e interreligioso entre la Iglesia Católica y los demás cristianos, así como el diálogo con grupos minoritarios de otras religiones, culturas indígenas y afroamericanas, indiferentes y ateos; pero -claro está- inicialmente se debe formar profundamente en estas iniciativas al conjunto de católicos, para no cometer errores con buenas intenciones, lo que ha sucedido en distintos escenarios, al pensar erróneamente, por ejemplo, que en el ecumenismo la primera y la última palabra la tienen los católicos.

El segundo camino se puede perfilar desde la necesaria insistencia para que el conjunto de creyentes, tanto jerarcas, líderes u organizadores, como fieles o creyentes en todos los ámbitos y desde los distintos estilos de vida, encarnen profundamente sus valores, pues solo así, mediante la mayor coherencia de vida, las religiones pueden hacer efectivo el potencial de paz que les es inherente. Este escenario -como contenido y como forma, siendo consecuentes- debe estar presente en las dinámicas de enseñanza religiosa, de tal manera que se repitan las valiosas propuestas norteamericanas y europeas, y que se den respuestas con asertividad y pertinencia a cada contexto.

\footnotetext{
${ }^{71}$ Morin, Introducción al pensamiento complejo, 32.

${ }^{72}$ Bonilla, "Un modelo pedagógico (aprendizaje dialógico y enseńanza dialogante) y un propósito (diálogo interreligioso y ecuménico). Retos a la educación religiosa escolar”.
} 
Al retomar la propuesta de educación para la paz de Jares, se confirma el incalculable caudal teológico y religioso aún sin explorar en profundidad, especialmente en los conceptos de verdad y esperanza. También tienen gran significación para la realidad colombiana en lo que pretenden atacar, pues resultan muy evidentes la mentira de la que se vale la clase política, en su mayoría, igual que la manipulación de distintos medios de comunicación e incluso en escenarios religiosos.

Del mismo modo, en Colombia existe una patológica "normalización" que sus habitantes expresan constantemente en "cansancio/desgaste" hacia el contexto que se vive y sus instituciones más comunes, acompañado de una visión negativa, como si se estuviera en un callejón sin salida y, por tanto, sin el deseo de buscar otras alternativas. Ante este escenario, la esperanza proveniente del orden religioso tiene aún mucho por decir y proponer ${ }^{74}$.

Para terminar, el gran reto de la educación religiosa escolar, ERE, y la formación integral hacia la que tienden las universidades consiste en romper con la pasividad en que parece estar imbuida la sociedad colombiana, en acrecentar la conciencia y el compromiso, en dejar de ser cómplices de la violencia y no permitir que la religión sea una de sus fuentes. Igualmente, convendría identificar que las disputas y dilemas que se presentan en el mundo de la vida tendrían que convertirse en manifestaciones de una fe madura, para que generen un resultado de transformación individual y social, al tiempo que un mayor conocimiento de la propia fe, mayor compromiso con la comunidad de vida y el contexto, así como una notable vivencia en coherencia con lo que se dice creer.

Del mismo modo, las teorías -tanto teológicas como educativas- dan luces para generar reflexiones críticas, mientras que las tradiciones religiosas proveen de un entramado de valores que harían posible el mundo que se desea, desde una profunda cultura de paz.

En la conjunción de estos propósitos, la educación religiosa en todos sus niveles puede aportar al objetivo de lograr la concienciación, la capacidad de superar la frustración que genera el conflicto cuando no es potenciado, para que se asuma de la mejor manera y se transforme en acciones que reflejen justicia social. Y desde la capacidad que tienen las religiones para construir comunidades de fe, comunidades solidarias y de vida, se pueden fomentar actitudes para superar la fragmentación social y así facilitar la convivencia en paz. Estos podrían ser algunos de los componentes que se necesitarían en los currículos (manifiestos u ocultos) de una educación religiosa escolar y una formación integral universitaria. 


\section{Bibliografía}

Angélico, José Pedro. "Humanismos, plataformas para la paz. Una lectura desde la teología trinitaria”. Cauriensia 8 (2013): 433-443.

Arboleda, Carlos. Guerra y religión en Colombia. Medellin: Universidad Pontificia Bolivariana, 2006.

. Pluralismo, tolerancia y religión en Colombia. Medellin: Pontificia Universidad Bolivariana, 2011.

Arendt, Hannah. Los orígenes del totalitarismo. Madrid: Alianza Editorial, 2006.

Bastian, Jean Pierre. "Las dinámicas contemporáneas de pluralización del campo religioso en América Latina". En Diversidad y dinámicas del cristianismo en América Latina, editado por A. E. González, 9-23. Bogotá: Editorial Bonaventuriana, 2007.

Bonilla Morales, Jaime Laurence. Educación religiosa escolar en perspectiva de complejidad. Bogotá: Editorial Bonaventuriana, 2015.

(ed.). Educación y religión: violencia y paz. Acercamiento al estado actual en diversos contextos. Bogotá: Editorial Bonaventuriana, 2015.

. "Teología del pluralismo religioso: paradigma y frontera". Franciscanum 156 (2011), 75-104.

. "Un modelo pedagógico (aprendizaje dialógico y enseñanza dialogante) y un propósito (diálogo interreligioso y ecuménico). Retos a la educación religiosa escolar". En Educación religiosa escolar y pedagogías para el reconocimiento del pluralismo religioso, por J. L. Bonilla y otros, 277-320. Bogotá: Editorial Bonaventuriana, 2014.

Bravo, Leonardo. "La pregunta por el sentido de la vida: la articulación esencial entre razón y fe". Scripta theologica Vol. 47 (2015): 643-668.

Cano, María José y Beatriz Molina. "Culturas, mundos globales y paz". Revista de paz $y$ conflictos 2, Vol. 8 (2015): 9-27.

Comins, Irene y Sonia París. "Epistemologías para el humanismo desde la filosofía para la paz”. Recerca 12 (2012): 5-11.

Consejo Nacional de Educación Superior. Acuerdo por lo Superior 2034. Propuesta de politica pública para la excelencia de la educación superior en Colombia en el escenario de la paz. Bogotá: CESU, 2014. 
Concilio Vaticano II. Constitución pastoral Gaudium et spes. Bogotá: San Pablo, 1995.

Díaz, Carlos. "Las preocupaciones del profesor de religión". Revista española de pedagogía 222 (2002): 301-318.

Dupuis, Jacques. Hacia una teología cristiana del pluralismo religioso. Santander: Sal Terrae, 2000. . Jesucristo al encuentro de las religiones. Madrid: San Pablo, 1991.

Freire, Paulo. "Conscientization”. Cross Currents 1, Vol. 24 (1974): 23-28.

Galtung, Johan. Paz por medios pacificos. Paz y conflicto, desarrollo y civilización. Bilbao: Gernika Gogoratuz, 2003. . Sobre la paz. Barcelona: Fontamara, 1985.

González, Andrés Eduardo (ed.). Diversidad y dinámicas del cristianismo en América Latina. Bogotá: Editorial Bonaventuriana, 2007.

Grupo Interdisciplinario de Estudios sobre Religión, Sociedad y Política, Giersp. Diversidad y dinámicas del cristianismo en América Latina. Memorias del II Congreso Internacional. Tomos 1 y 2. Bogotá: Editorial Bonaventuriana, 2009.

- "Encuesta de permanencia y cambios de la identidad política y religiosa en Bogotá”. Franciscanum 152, Vol. LI (2009): 209-274.

. Mirada pluridisciplinar al hecho religioso en Colombia: avances de investigación. Bogotá: Editorial Bonaventuriana, 2009.

Jaime Contreras, Miguel Humberto. "El conflicto armado en Colombia". Revista de derecho 19 (2003): 119-125.

Jaramillo Marín, Jefferson. "Expertos y comisiones de estudio sobre la violencia en Colombia”. Estudios políticos 39 (2011): 231-258.

Jares, Xesús. Educación para la paz. Su teoría y su práctica (3a. ed.). Madrid: Editorial Popular, 2005.

. Educación y conflicto. Guía de educación para la convivencia. Madrid: Editorial Popular, 2001.

. Educar para la verdad y la esperanza. En tiempos de globalización, guerra preventiva y terrorismos. Madrid: Editorial Popular, 2005.

Knitter, Paul. Introducción a las teologias de las religiones. Estella (Navarra): Verbo Divino, 2007. 
Küng, Hans. Teología para la posmodernidad. Fundamentación ecuménica. Madrid: Alianza Editorial, 1989.

Lederach, John Paul. El abecé de la paz y los conflictos. Educación para la paz. Madrid: Catarata, 2000.

. "Experto internacional habla sobre la reconciliación en Colombia". www. youtube.com/watch?v=Thx0-vXf3Ks (consultado el $1^{\circ}$ de agosto de 2015).

Mallimaci, Fortunato (dir.). "Primera encuesta sobre creencias y actitudes religiosas en Argentina (agosto de 2008)". Ceil-Conicet, www.ceilpiette.gov.ar/areasinv/ religion/relproy/1encrel.pdf (consultado el 20 de febrero de 2012).

Marzal, Manuel. Tierra encantada. Tratado de antropología religiosa de América Latina. Madrid: Trotta, 2002.

Meza Rueda, José Luis (dir.). Educación religiosa escolar. Naturaleza, fundamentos y perspectivas. Bogotá: San Pablo-PUJ, 2011.

Meza Rueda, José Luis y Gabriel Suárez (eds.). Educar para la libertad. Una propuesta de educación religiosa escolar en perspectiva liberadora. Bogotá: San Pablo, 2013.

Morin, Edgar. Introducción al pensamiento complejo. Barcelona: Gedisa, 1998.

Muntaner i Gelabert, Guillem. "La religión en la filosofía contemporánea”. En El hecho religioso: datos, estructura, valoración, editado por Vicente Martín Pindado. Madrid: Editorial CCS, 1996.

Observatorio para la Paz. “¿Quiénes somos?”. Obserpaz, www.obserpaz.org/quienessomos.shtml?apc=b-1-comosurgio-- $\& \mathrm{x}=322$ (consultado el 14 de abril de 2014).

Parra Mora, Alberto. "De camino a la teología de la acción". Theologica Xaveriana 175, Vol. 63 (2013): 143-171.

Peace Accords Matrix. "Explore peace agreements and their implementation around the world". University of Notre Dame, https://peaceaccords.nd.edu (consultado el 13 de junio de 2015).

Reconciliación Colombia. "Las armas son el fracaso de la palabra”. Reconciliación Colombia, http://reconciliacioncolombia.com/historias/detalle/951/las-armas-son-elfracaso-de-la-palabra (consultado el 30 de julio de 2015).

República de Colombia. "Ley 1732 de 2014”. Presidencia de la República, http://wsp. presidencia.gov.co/Normativa/Leyes/Documents/LEY\%201732\%20DEL\%20 01\%20DE\%20SEPTIEMBRE\%20DE\%202014.pdf (consultado en octubre 4 de 2014). 
Salazar, Fabián. "Retos de la cooperación interreligiosa en Colombia en favor de la paz". En El diálogo interreligioso. Iniciativas para la gestión de la diversidad religiosa, coordinado por Carmen Castilla Vázquez, 111-130. Granada: Comares, 2011.

Sánchez, Gonzalo (coord.). Comisión de estudios sobre la violencia. Colombia: violencia y democracia. Medellín: La Carreta, 2009.

Sánchez Hernández, Olvani Fernando. "Reconocimiento de la pluralidad. El desafío de la relatividad en los discursos teológicos". Franciscanum 145, Vol. XLIX (2007): 65-79.

Tamayo Acosta, Juan José. Fundamentalismo y diálogo de religiones. Madrid: Trotta, 2004.

Torres Queiruga, Andrés. Diálogo de las religiones y autocomprensión cristiana. Santander: Sal Terrae, 2005.

Vilanova, Evangelista. "Una manipulación de la teología de la paz: las cruzadas medievales". Ilu. Revista de ciencias de las religiones VI (2001): 169-173.

Villalobos, José. "Educación y concientización: legados del pensamiento y acción de Paulo Freire". Educere 10, Vol. 4 (2000): 17-24.

Zuleta, Estanislao. Colombia: violencia, democracia y derechos humanos (4a. ed.). Medellín: Hombre Nuevo, 2005. 